\title{
Research on Biotic and Abiotic Stress Related Genes Exploration and Prediction in Brassica rapa and B. oleracea: A Review
}

\author{
Md. Abdul Kayum ${ }^{1}$, Hoy-Taek Kim ${ }^{1}$, Ujjal Kumar Nath ${ }^{1}$, Jong-In Park ${ }^{1}$, Kang Hee Kho ${ }^{2}$, Yong-Gu Cho ${ }^{3}$, Ill-Sup Nou ${ }^{1}$ * \\ ${ }^{1}$ Department of Horticulture, Sunchon National University, Suncheon 57922, Korea \\ ${ }^{2}$ Department of Fisheries Science, College of Fisheries and Ocean Sciences, Chonnam National University, Yeosu 59626, Korea \\ ${ }^{3}$ Department of Crop Science, Chungbuk National University, Cheongju 28644, Korea
}

\begin{abstract}
Global population is increasing day-by-day, simultaneously, crop production need to increase proportionately. Whereas, increase crop production being restricted due to abiotic and biotic stresses. Abiotic stresses are adversely affected crop growth and development, leading to crop loss globally and thereby causing huge amount of economic loss as well. Contrary, pathogens are attacked the plants imposing biotic stress and severely hampers the yield. Therefore, it is prime need to understand the molecular mechanism and genes involved to minimize the biotic and abiotic stresses for mitigating the Brassica vegetable crop losses. The stress responsive, pathogens related genes are involved in tolerance or resistance to stress in plants that are cross-talk with different types of stress components in signal transduction pathways. The plants have their own mechanism to overcome biotic and abiotic stresses to follow the abscisic acid (ABA)-dependent and ABA-independent pathways. Several transcription factors such as WRKY, Alfin-like, MYB, NAC, DREB, CBF are integrating to various stress signals and controlling the gene expression through networking with their related cis-elements. To develop stress tolerance and/or resistant crops plants, there is need to realize both of the plant and pathogenic disease development mechanisms. Therefore, this article is focused on (i) major and devastating stresses on vegetable crops, (ii) role of genes to overcome the stresses, and (iii) differential genes expressed under biotic and abiotic stresses in Brassica oleracea and B. rapa for getting insight of the mechanisms of development of resistance lines.
\end{abstract}

Keywords Biotic and abiotic stress, Gene expression, Transcription factor, Brassica

\section{INTRODUCTION}

The concept of stresses on plant is "unfavorable and environmental constraints in plants" or "all agents can act as stressors, producing both stress and specific action," and "there exist stressor-specific responses and non-specific general responses" (Haag 2013). Brassica crops have experience many different types of stresses. Those are biotic stresses like fungal, bacterial, viral diseases and insect pests, while abiotic stresses are salinity, extremes temperature (cold, heat), water shortage (drought or dehydration), water logging, etc. The plant can respond to abiotic stresses not only by fast acclimations but also by particular long term adaptations such as leaf shape, size and thickness, stomata density and distribution, chloroplast structure and function by increasing the levels of photo- protecting enzymes and stress metabolites (Obidiegwu et al. 2015). These types of adaptation may take place within few days or in a week depending on plant nature. Biotic stress is the result of damage of plants occurs by other living organisms, such as bacteria, viruses, fungi, parasites, insects, weeds, and cultivated or native plants. Abiotic stress is the lifeless factors on the living organisms in a specific environment. The lifeless variable must control the environment beyond its normal range of variation to unfavorably affect the population performance or individual physiology of the organism in a significant way. The biotic and abiotic stresses are very importance for crop production worldwide; it's significantly reducing the yield of crops. These stresses are major constraints for crop growth, which consequently hampers the productivity of crop plants. Crops yield are reduced about $25 \%$ worldwide

Received May 17, 2016; Revised May 24, 2016; Accepted May 25, 2016; Published May 31, 2016

*Corresponding author Ill-Sup Nou, nis@sunchon.ac.kr, Tel: +82-61-750-3249, Fax: +82-61-750-3208 
due to diseases and insects infestation (Savary et al. 2012). Globally, abiotic stress is the key sources of crop loss, reducing more than $50 \%$ average yields for most major crop plants (Acquaah 2007). Particularly, drought and salinity are becoming devastating in many regions of the world, and may cause serious salinization of more than 50\% of all arable lands by the year 2050" (Wang et al. 2003).

However, the biotic stress is one of the important features that have significant effect on crop growth and development and ultimately responsible for huge losses of crop yield. Moreover, abiotic stress is another confronts inducing a strong pressure on crop production. Now-a-days, research has generally centralize on understanding plant responses to abiotic or biotic stresses (Qin et al. 2011; Todaka et al. 2012; Thakur and Sohal 2013; Stotz et al. 2014). In the field condition, plants have to face more than one stress simultaneously, and the response cannot be predicted based on the plant's response to the individual single stresses (Atkinson and Urwin 2012). Plants can demonstrate different levels of sensitivity depending on the natural condition and the developmental stage of the plant (Mittler and Blumwald 2010). Different type of interactions can take place between the defenses mechanism after sensitivity of the stresses. It is confusing, whether biotic and abiotic stresses are rather antagonistic, synergistic or additive, inducing more or less susceptibility to a specific kind of stress. In most of the times, exposed on different type of stresses can also lead to antagonistic responses in the plants (Yasuda et al. 2008; Ton et al. 2009), for examples, under drought stress condition common beans show more symptoms when infected by Macrophomina phaseolina (Suleman et al. 2001) and applied ABA on tomato leaves increases the susceptibility to Botrytis cinerea (Audenaert et al. 2002).

Brassica is a very important vegetable group worldwide which comprises some 100 species, including rapeseed (Brassica napus L.), mustard (Brassica juncea L.), cabbage (Brassica oleracea L.), and turnip rape (Brassica rapa L.) that are mainly grown for oil, condiments, vegetables or fodder (Ashraf and McNeilly 2004). These crops are sternly challenged by biotic stresses (fungal and bacterial pathogens, viral diseases) and abiotic stresses including drought, heat, cold or salinity are the major factors that cause enormous losses of yield. Fusarium oxysporum is the plant pathogen that infects Brassica crops causing the wilt disease leading to great loss in quantity and quality of oilseed Brassica (Gaetan 2005). The blackleg or stem cankers causing pathogen Leptosphaeria maculans is the most devastating fungal diseases for oilseed Brassica, particularly canola (B. napus and B. rapa) (Howlett et al. 2001; Fitt et al. 2006). Brassica vegetables are highly susceptible to bacterial soft rot disease which is the most severe and destructive disease that causes serious damage and economic losses across the members of Brassica. Many abiotic stresses directly or indirectly affect the Brassica crops, due to the fact that they are mainly grown in arid and semiarid areas. However, its growth and yield have greatly decreased owing to abiotic stresses.

Most of the Brassica species were grown normally at $15^{\circ} \mathrm{C}-22^{\circ} \mathrm{C}$ temperature. The above $35^{\circ} \mathrm{C}$ temperature and below $10^{\circ} \mathrm{C}$ temperature was injurious to reproductive organs at different developmental stages of Brassica crops (Angadi et al. 2000). B. rapa was more sensitive to heat stress than B. napus and B. juncea. However, generally the Brassica spp. of tropical and subtropical origins is sensitive to chilling $\left(0^{\circ} \mathrm{C}-15^{\circ} \mathrm{C}\right)$ and freezing $\left(<0^{\circ} \mathrm{C}\right)$ stress and lacks this mechanism of cold acclimation (Sanghera et al. 2011).

Stresses could be managed in two ways in vegetable crops I. Crop management II. Biotechnological approaches. Abiotic stress effects can be managed by agronomic practices such as irrigation by quality water, soil amendment, altering sowing time, etc. This strategy is not sustainable and economic for vegetable production (Farooq et al. 2009). Therefore, we need the permanent solution for vegetable production against stresses. Plants have their own defense mechanism that regulate the expression of stress related genes will be necessary for the stress tolerance crop variety development (Dita et al. 2006). Exposure of plants to biotic and abiotic stress leads to the adjustment of stresses using their genetical mechanism and produced high yield during stress condition. On the other hand, when plants face up to adverse conditions, few genes are active against such stresses, researcher are used this active genes to developed stress tolerance crop varieties. Therefore, this review has focused to explore the probable genes for specific stresses. 


\section{MAJOR AND DEVASTATING STRESSES ON VEGETABLE CROPS}

The global warming trend is expected to continue and changes in temperature, precipitation and carbon dioxide that will affect plant growth and development, spread of pests and diseases and influence the environmental factors on vegetable crops production. Globally, vegetables crops yield are reduced more than $50 \%$ due to abiotic stresses (Bray et al. 2000). Climatic changes will influence the severity of abiotic stress imposed on vegetables crops. The genera Brassica are an important and diverse vegetable crops grown worldwide, include a number of economically important crops such as B. rapa, B. oleracea, B. napus, etc. (Cardoza and Stewart 2004) and these crop plants are affected by biotic and abiotic stresses. The Brassica vegetables are soft and succulent and generally consist of more than $85 \%$ water. Therefore, water scarcity as well as excessive water significantly influences the yield and quality of these crops; abiotic stress particularly cold, salinity and drought stresses dramatically reduce productivity of these crops. Different types of stresses are faced by Brassica vegetables during their growth cycle and try to overcome those stresses by adapting or producing different mechanisms (Table 1).

Cold is one of the devastating stresses for Brassica vegetable crops. Under cold stress condition, water in plant body become ice and rupture the plant cell, ultimately significant yield losses with great risks for future global food security. Cold stress is even more destructive stress when it imposed in seedling and reproductive stages. Drought stress causes an increase of solute concentration in the soil, leading to an osmotic flow of water out of plant cells. Extreme drought stress conditions will negatively impact on crop yield. Due to soft and succulent in nature of the cabbage family, majority numbers of the vegetable crops are sensitive to drought stress, mainly during flowering and seed development stages.

Salinity is also the similar trends of problem like drought for vegetables crops. It is projected that about $17 \%$ and $30 \%$ of cultivated lands and irrigated agricultural land of the worldwide are affected by high salinity, respectively (Vijayvargiya and Kumar 2011). In tropical areas, high evapo-transpiration results in substantial water loss due to hot and dry environments, thus leaving salt around the plant roots which interferes with the plants ability to uptake

Table 1. Enlist different types of stresses normally induced threat to vegetable cultivation and their possible causes and responses for combat against such stresses.

\begin{tabular}{|c|c|c|}
\hline Types of stress & Agent & Probable response \\
\hline \multirow[t]{2}{*}{ Biotic } & Bacteria & $\begin{array}{l}\text { Plant produce callogen and tyloses which is responsible against Bacterial } \\
\text { pathogens. }\end{array}$ \\
\hline & Fungi & Formation of ROS which activated against fungi. \\
\hline \multirow[t]{6}{*}{ Abiotic } & Low temperature (chilling) & $\begin{array}{l}\text { Activated DREB } 1 / \mathrm{CBF} \text { genes and produce detoxification of ROS and } \\
\text { altering glyoxalate pathway that developed low temperature tolerance } \\
\text { plants. }\end{array}$ \\
\hline & High salinity & $\begin{array}{l}\text { WRKY, NAC, MYB TFs activated salt resistant genes that altering } \\
\text { glyoxalate pathway and waxy layer formation; finally produce salinity } \\
\text { resistant plants. }\end{array}$ \\
\hline & Drought/water shortage & Stomatal closure reduces transpiration that manages the drought stress. \\
\hline & Heat & Efficient protein repair systems and general protein stability support \\
\hline & $\begin{array}{l}\text { Natural mineral deficiency } \\
\text { (e.g., nitrogen shortage) }\end{array}$ & survival, temperature can lead to acclimation. \\
\hline & Water logging & $\begin{array}{l}\text { Development of cavities mostly in the roots that facilitate the exchange } \\
\text { of oxygen and ethylene between shoot and root (aerenchyma). }\end{array}$ \\
\hline \multirow{2}{*}{$\begin{array}{l}\text { Hormonal } \\
\text { factors }\end{array}$} & SA & SA regulated the stomatal closure that directly involved in drought stress. \\
\hline & $\mathrm{JA}$ and $\mathrm{ABA}$ & JA uses as stress signaling \\
\hline
\end{tabular}

ROS: reactive oxygen species, SA: salicylic acid, JA: Jasmonic acid, ABA: abscisic acid. 
water. Under salt stress, plant is reflected in loss of turgor, growth reduction, wilting, leaf curling, leaf abscission, decreased photosynthesis, respiratory changes, loss of cellular integrity, tissue necrosis and potentially death of the plant (Cheeseman 1988). Most of the vegetable crops especially Brassica crops are sensitive to salinity stress during seedling and early growing stages. Therefore, it is well characterized that the response of plants to abiotic stresses depends on the plant growing stage and the duration and severity of the stress (Bray 2002).

Like abiotic stresses, Brassica are also highly susceptible to several biotic stresses. Fusarium wilt, Club root, soft rot, Black rot are the importance diseases (Ahmed et al. 2012a; Kayum et al. 2015a). Two pathogens Pectobacterium carotovorum subsp. carotovorum and F. oxysporum f.sp. conglutinans are specifically attacked Brassica crops and cause soft rot and Fusarium wilt diseases. Bacterial soft rot and Fusarium wilt are the most severe and destructive disease, which causes huge damage and enormous losses across the members of Brassica. Control of this pathogen is difficult due to its wide range of host's selectivity and to survive on plant debris. These two diseases break out devastatingly when attack at seedling stage (Ahmed et al. 2012a). Many plant defense or defense-related genes contain W-box sequences in their promoters region, including pathogenesis-related (PR) genes and the regulatory NPRI gene (Yu et al. 2001). The W-box sequences are necessary for the inducible expression of these defense genes.

\section{ROLE OF GENES TO OVERCOME THE ABIOTIC STRESSES}

Plants are developed different defense mechanism through activation of complex signaling cascade in varying stress conditions (Abou Qamar et al. 2009). Plant exposed to abiotic and biotic stresses, promote to activate protein kinase cascades and specific ion channels keep

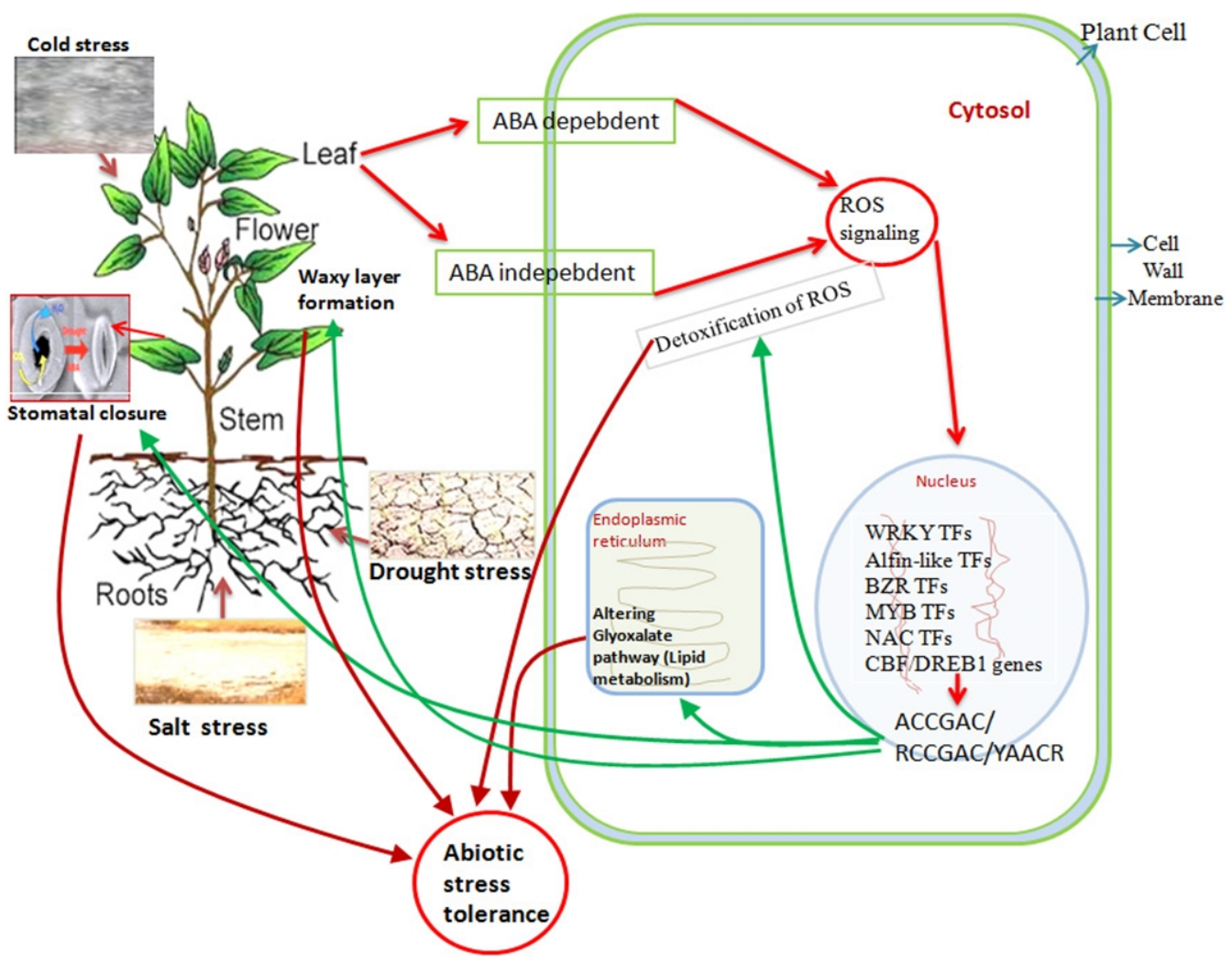

Fig. 1. Simple model of different signaling pathway involved in plants to overcome the abiotic stresses. ABA: abscisic acid, ROS: reactive oxygen species. 
turn on, or producing reactive oxygen species (ROS), phytohormones such as salicylic acid, jasmonic acid, abscisic acid (ABA), etc. (Fujita et al. 2006). A simple model has been proposed in Fig. 1, where different mechanisms of responses to abiotic stresses by plants along with their corresponding are presented for better understanding.

According to our present knowledge on stress signaling pathways, the transcriptional regulatory networks of abiotic stress signals and gene expression have been studied (Chaves et al. 2003; Yamaguchi-Shinozaki and Shinozaki 2006; Pérez-Clemente et al. 2013). The major findings of those reports can be divided into the following major steps: signal perception, signal transduction, transcription factors activation, activation of cis-acting elements, stress responsive gene expression. Plant cell sensors or receptors located in the cell wall or membrane which perceive stress stimuli. Abiotic stress signal transduction is taken place through (i) ABA-dependent and (ii) ABA-independent pathways. In the ABA-dependent pathway, $\mathrm{ABRE}$ is the main $\mathrm{ABA}$ responsive elements that activate the stress responsive genes. On the other hand, in the ABA-independent pathway dehydration responsive elements (DRE) is involved in drought, cold and salt stress responsive genes regulation (Fig. 1). These signals are received by cell membrane sensors that pass from plants when they faced the abiotic stresses, accordingly cells try to response the signals through producing ROS, calcium ions, inositol phosphate etc. inside the cells. However, high level of ROS in intracellular space may cause damage the lipid, protein and finally DNA. Moreover, phosphorylation mediated by protein kinase help to activated or suppressed different numbers of transcription factors (TFs) and bind specifically to cis-acting elements in the stress-responsive genes promoters and control their transcriptional level for combat against abiotic stresses (Danquah et al. 2014).

In the meantime, other upstream components are control TFs at the transcription level (Hirayama and Shinozaki 2010) and subjected to different levels modifications at the post-transcription stage, such as ubiquitination and sumoylation, thus forming a complex regulatory network that control the stress responsive genes expression level. These genes are involved in detoxification of ROS, altering glyoxalate pathway, stomatal closure, waxy layer formation (Dong et al. 2006; Miura et al. 2007; Mizoi et al. 2013). Therefore, breeder should keep in consideration of the above mentioned components in the Fig. 1, from signal receptors to the downstream stress responsive genes that constitute the generic pathway for plant abiotic stress signal transduction (Fig. 1) for developing abiotic stress tolerance cultivars.

\section{DIFFERENTIAL GENES EXPRESSED UNDER ABIOTIC STRESSES IN Brassica}

The abiotic stresses are becoming alarming situation for Brassica crop production worldwide due to quickly changes of global environment. Previous studies have showed that different genes are differentially expressed under such type of stresses in B. rapa and B. oleracea. WRKY and Alfin-like transcription factors have been well documented in response to many abiotic stresses in B. rapa (Kayum et al. 2015a; 2015b). Among the WRKY genes, BrWRKY22, BrWRKY44, BrWRKY70, and BrWRKY72 in Chiifu showed about 175-, 32-, 54-, and 42-fold higher expressions, respectively during cold stress. Therefore, BrWRKY22, BrWRKY44 genes could be introgressed or over-expressed in B. rapa vegetables for getting cold tolerant lines. Additionally, under salt stress condition, BrWRKY17, 57, and 58 showing about 5-, 2-, and 3-fold higher expression, respectively and $B r W R K Y 51,65,98$, and 104 showed their highest expression after drought stress treatment and were about 85-, 15-, 18-, and 38-fold higher than the control, respectively (Kayum et al. 2015a). On the other hand, BrAL2, 3, 7, 9, 12,13, 14, and 15 showed higher expression in response to all abiotic stresses (cold, salt, and drought) (Kayum et al. 2015b). Lee et al. (2012) found that all eight $\mathrm{CBF} / \mathrm{DREB} 1$ genes responses against cold stress and some of them also responsive to salt, drought and $\mathrm{ABA}$ treatment. Several numbers of NAC TFs are involved in various abiotic stress of Chinese cabbage (Liu et al. 2014). Several numbers of BZR transcription factor and longevity assurance gene of $B$. rapa showed responsiveness against cold, drought and ABA stresses (Ahmed et al. 2012c; Saha et al. 2015). Alfine-like transcription factors in B. oleracea 
(BoAL1, 4, 5, 6, 7, 8, 9, 10, and 12) have been reported in response to abiotic stresses like cold, salinity, drought and ABA (Kayum et al. 2016) and Wang et al. (2015) showed that BrMYB210, BrMYB137, BrMYB88, BrMYB154, and $B r M Y B 222$ significantly responses against cold and osmotic stress and BrMYB261 (an ortholog of AtMYB28) had no response to cold treatment, but was expressed dramatically by osmotic stress. Among the MYB genes, six genes (BrMYB140, BrMYB172, BrMYB229, BrMYB208, $B r M Y B 137$, and $B r M Y B 210)$ were significantly up-regulated by $\mathrm{ABA}$ treatment but down-regulated by auxin treatment. However, BrMYB210 (an ortholog of AtMYB96) showed down-regulation against auxin treatment in leaves (Wang et al. 2015). Ahmed et al. (2015) showed that 12 BoCRGs were expressed differentially after cold stress treatment in two contrasting cabbage lines, and BoCRG54, 56, 59, 62, 70, 72, and 99 were predicted to be involved in cold regulatory pathways.

\section{ROLE OF GENES TO OVERCOME THE BIOTIC STRESSES}

Plants have two levels of immune system that protects them against different types of pathogens. At the first, a pattern recognition receptor (PRR) recognizes pathogens attacks on the surface of the plant cell. The PRR produces signaling and pass to nucleus that activate defense related genes. Thereby, the cells are tried to stop further invasions of the pathogens through producing huge amount of callose, tyloses and ROS. Plant cells are deposited callose and tyloses just inside cell wall, resulting in cell walls thicker which protect the microorganisms (Fig. 2). Secondly, the plant cells are started secretion of high amount of ROS and activation of pathogenesis related (PRs) damaging threatening pathogens (Kumar 2013). At the same time, pathogens also are injecting sets of affecter molecule inside the cell that try to damage or defeat the plant immunity system. The affecter molecules damaging transduction signaling and response that disrupt plant defense system and ultimately plants are infected by

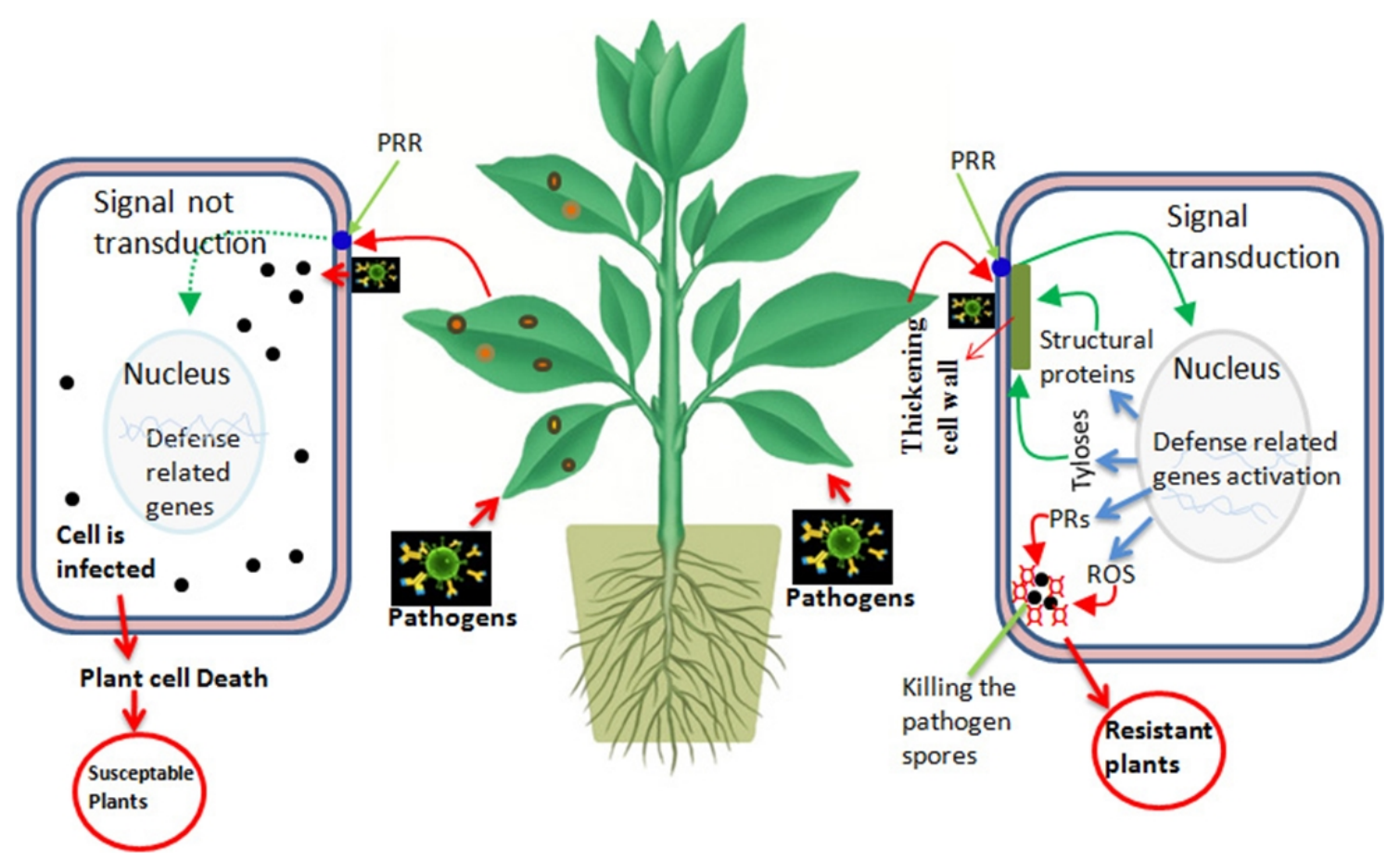

Fig. 2. Schematic model of plant-pathogen interaction and molecular mechanisms involved in resistance and susceptible reactions to pathogens attacks.

PRR: pattern recognition receptor, PRs: pathogenesis related, ROS: reactive oxygen species. 
pathogens in susceptible plants (Fig. 2; Oppel et al. 2009).

\section{DIFFERENTIAL GENES EXPRESSED UNDER BIOTIC STRESSES IN Brassica}

Biotic stress is very devastating stress for plants as well as vegetables crops. Several numbers of genes have well documented that they are differentially expressed against different biotic stresses. However, when infection with $F$. oxysporum f.sp. conglutinans, six BrWRKY genes (BrWRKY4, 65, 72, 97, 133, and 141) showed significantly higher expression and were about 8-, 6-, 6-, 3-, and 5-fold higher, respectively (Kayum et al. 2015a). BrWRKY141 showed about 180-fold higher expression after $P$. carotovorum subsp. carotovorum infection (Kayum et al. 2015a). After infection with $F$. oxysporum f. sp. conglutinans, BrAL2, 3, 4, 7, 9, 10,13,14, and 15 showed several fold higher expression, and $B r A L 2,3,7,9,13,14$, and 15 were expressed in response to both biotic and abiotic stresses (Kayum et al. 2015b). Ahmed et al. (2012a) reported that three chitinase genes $(B r C L P 1, B r C L P 2$, and $B r C L P 3)$ responses against $P$. carotovorum subsp. carotovorum infection. The defensin-like family protein (BrDLFP) expression significantly increased after infection with $P$. carotovorum subsp. carotovorum in Chinese cabbage (Ahmed et al. 2012b). On the other hand, Alfin-like two genes (BoAL8 and BoAL12) were induced after infection with $P$. carotovorum subsp. carotovorum in B. oleracea (Kayum et al. 2016). Among the 12 thaumatin-like proteins, three of which expressed differentially after P. carotovorum subsp. carotovorum infection in cabbage plants (Ahmed et al. 2013).

\section{CONCLUSIONS}

Crop growth, development and yields are severely affected by environmental cues and different types of pathogens. Most of the vegetables crops are vulnerable to those stresses. The cellular metabolic components calcium, ROS, protein kinase, protein phosphatase are activated and promotes signal transduction pathways inside cells during stress and convey the abiotic stress signal that are necessary to regulate TFs. The TFs are controlled the downstream genes that regulate the abiotic stress through activate their corresponding cis-acting elements. On the other hand, biotic stress signals are responded by the plants through initiation of callogen, ROS, tyloses, etc. in the signal transduction pathways. Plant cells are received the external signal of each stress and consequently turn on the responsive to produce particular molecules to over-come such stress. Some molecules are involved in the defense response to the specific stress that contributes to protect the plant and express its resistance/tolerance to that stress. The molecular engineering is a new approach which is used to modify a gene coding and introduction specific genes in crop plants leading to increase tolerances against stresses. We need to understand the functions or mechanisms of the stress responsive candidate genes. Thereafter, introgression of those candidate genes through conventional breeding or marker assisted back crossing or even in urgent situation genetic transformation will lead to develop resistance or tolerance cultivar of B. oleracea and B. rapa.

\section{ACKNOWLEDGEMENTS}

This research was supported by the Golden Seed Project (No. 213003-04-4-SB110) of the Ministry of Agriculture, Food and Rural Affairs (MAFRA) of the Republic of Korea.

\section{REFERENCES}

Abuqamar S, Luo H, Laluk K, Mickelbart MV, Mengiste T. 2009. Crosstalk between biotic and abiotic stress responses in tomato is mediated by the AIM1 transcription factor. Plant J. 58: 347-360.

Acquaah G. 2007. Principles of plant genetics and breeding. Blackwell, Oxford, p.385.

Ahmed NU, Jung HJ, Park JI, Cho YG, Hur Y, Nou IS. 2015. Identification and expression analysis of cold and freezing stress responsive genes of Brassica oleracea. 
Gene 554: 215-223.

Ahmed NU, Park JI, Jung HJ, Chung MY, Cho YG, Nou IS. 2013. Characterization of thaumatin-like gene family and identification of Pectobacterium carotovorum subsp. carotovorum inducible genes in Brassica oleracea. Plant Breed. Biotech. 1: 111-121.

Ahmed NU, Park JI, Seo MS, Kumar TS, Lee IH, Park BS, et al. 2012a. Identification and expression analysis of chitinase genes related to biotic stress resistance in Brassica. Mol. Biol. Rep. 39: 3649-3657.

Ahmed NU, Park JI, Jung HJ, Seo MS, Kumar TS, Lee IH, et al. 2012b. Identification and characterization of stress resistance related genes of Brassica rapa. Biotechnol. Lett. 34: 979-987.

Ahmed NU, Park JI, Jung HJ, Lee IH, Song IJ, Yang SY, et al. 2012c. Identification and characterization of longevity assurance gene related to stress resistance in Brassica. Afr. J. Biotechnol. 11: 12721-12727.

Angadi SV, Cutforth HW, Miller PR, McConkey BG, Entz MH, Brandt SA, et al. 2000. Response of three Brassica species to high temperature stress during reproductive growth. Can. J. Plant Sci. 80: 693-701.

Ashraf M, McNeilly T. 2004. Salinity tolerance in Brassica oilseeds. Crit. Rev. Plant Sci. 23: 157-174.

Atkinson NJ, Urwin PE. 2012. The interaction of plant biotic and abiotic stresses: From genes to the field. J. Exp. Bot. 63: 3523-3543.

Audenaert K, De Meyer GB, Höfte MM. 2002. Abscisic acid determines basal susceptibility of tomato to Botrytis cinerea and suppresses salicylic acid-dependent signaling mechanisms. Plant Physiol. 128: 491-501.

Bray EA, Bailey-Serres J, Weretilnyk E. 2000. Responses to abiotic stresses. p.1158-1249. In: W. Gruissem, B. Buchannan, R. Jones (ed.). Biochemistry and molecular biology of plants. ASPP, Rockville, MD.

Bray EA. 2002. Classification of genes differentially expressed during water-deficit stress in Arabidopsis thaliana: an analysis using microarray and differential expression data. Ann. Bot. 89: 803-811.

Cardoza V, Stewart CN Jr. 2004. Brassica biotechnology: Progress in cellular and molecular biology. In Vitro Cell. Dev. Biol. Plant 40: 542-551.

Chaves MM, Maroco JP, Pereira JS. 2003. Understanding plant responses to drought: From genes to the whole plant. Funct. Plant Biol. 30: 239-264.
Cheeseman JM. 1988. Mechanisms of salinity tolerance in plants. Plant Physiol. 87: 547-550.

Danquah A, de Zelicourt A, Colcombet J, Hirt H. 2014. The role of ABA and MAPK signaling pathways in plant abiotic stress responses. Biotechnol. Adv. 32: 40-52.

Dita MA, Rispail N, Prats E, Rubiales D, Singh KB. 2006. Biotechnology approaches to overcome biotic and abiotic stress constraints in legumes. Euphytica 147: 1-24.

Dong CH, Agarwal M, Zhang Y, Xie Q, Zhu JK. 2006. The negative regulator of plant cold responses, HOS1, is a RING E3 ligase that mediates the ubiquitination and degradation of ICE1. Proc. Natl. Acad. Sci. U.S.A. 103: 8281-8286.

Farooq M, Wahid A, Kobayashi N, Fujita D, Basra SMA. 2009. Plant drought stress: Effects, mechanisms and management. Agron. Sustain. Dev. 29: 185-212.

Fitt BDL, Brun H, Barbetti MJ, Rimmer SR. 2006. Worldwide importance of phoma stem canker (Leptosphaeria maculans and L. biglobosa) on oilseed rape (Brassica napus). Eur. J. Plant Pathol. 114: 3-15.

Fujita M, Fujita Y, Noutoshi Y, Takahashi F, Narusaka Y, Yamaguchi-Shinozaki K, et al. 2006. Crosstalk between abiotic and biotic stress responses: a current view from the points of convergence in the stress signaling networks. Curr. Opin. Plant Biol. 9: 436-442.

Gaetán SA. 2005. Occurrence of Fusarium wilt on canola caused by Fusarium oxysporum f. sp. conglutinans in Argentina. Plant Dis. 89: 432.

Haag J. 2013. Improving photosynthetic efficiency in sports turf. Xlibris Corporation, Bloomington, IN. p.43.

Hirayama T, Shinozaki K. 2010. Research on plant abiotic stress responses in the post-genome era: Past, present and future. Plant J. 61: 1041-1052.

Howlett BJ, Idnurm A, Pedras MS. 2001. Leptosphaeria maculans, the causal agent of blackleg disease of Brassicas. Fungal Genet. Biol. 33: 1-14.

Kayum MA, Jung HJ, Park JI, Ahmed NU, Saha G, Yang TJ, et al. 2015a. Identification and expression analysis of WRKY family genes under biotic and abiotic stresses in Brassica rapa. Mol. Genet. Genomics 290: 79-95.

Kayum MA, Park JI, Ahmed NU, Jung HJ, Saha G, Kang JG, et al. 2015b. Characterization and stress-induced expression analysis of Alfin-like transcription factors in Brassica rapa. Mol. Genet. Genomics 290: 1299-1311.

Kayum MA, Park JI, Ahmed NU, Saha G, Chung MY, Kang 
JG, et al. 2016. Alfin-like transcription factor family: Characterization and expression profiling against stresses in Brassica oleracea. Acta Physiol. Plant. 38: 127.

Kumar S. 2013. Defence mechanism in plants: Phase I [Internet]. Google Blogger. [cited 2016 May 16]. Available from: http://sanjeetbiotech.blogspot.kr/2013/03/defence-mech anism-in-plants-phase-i.html.

Lee SC, Lim MH, Yu JG, Park BS, Yang TJ. 2012. Genome-wide characterization of the CBF/DREB1 gene family in Brassica rapa. Plant Physiol. Biochem. 61: 142-152.

Liu T, Song X, Duan W, Huang Z, Liu G, Li Y, et al. 2014. Genome-wide analysis and expression patterns of NAC transcription factor family under different developmental stages and abiotic stresses in Chinese cabbage. Plant Mol. Biol. Rep. 32: 1041-1056.

Mittler R, Blumwald E. 2010. Genetic engineering for modern agriculture: Challenges and perspectives. Annu. Rev. Plant Biol. 61: 443-462.

Miura K, Jin JB, Lee J, Yoo CY, Stirm V, Miura T, et al. 2007. SIZ1-mediated sumoylation of ICE1 controls CBF3/DREB1A expression and freezing tolerance in Arabidopsis. Plant Cell 19: 1403-1414.

Mizoi J, Ohori T, Moriwaki T, Kidokoro S, Todaka D, Maruyama K, et al. 2013. GmDREB2A;2, a canonical DEHYDRATION-RESPONSIVE ELEMENT-BINDING PROTEIN2-type transcription factor in soybean, is posttranslationally regulated and mediates dehydrationresponsive element-dependent gene expression. Plant Physiol. 161: 346-361.

Obidiegwu JE, Bryan GJ, Jones HG, Prashar A. 2015. Coping with drought: Stress and adaptive responses in potato and perspectives for improvement. Front. Plant Sci. 6: 542.

Oppel CB, Dussourd DE, Garimella U. 2009. Visualizing a plant defense and insect counterploy: Alkaloid distribution in Lobelia leaves trenched by a plusiine caterpillar. J. Chem. Ecol. 35: 625-634.

Pérez-Clemente RM, Vives V, Zandalinas SI, López-Climent MF, Muñoz V, Gómez-Cadenas A. 2013. Biotechnological approaches to study plant responses to stress. Biomed. Res. Int. 2013: 654120.

Qin F, Shinozaki K, Yamaguchi-Shinozaki K. 2011. Achievements and challenges in understanding plant abiotic stress responses and tolerance. Plant Cell Physiol. 52: 1569-1582.
Saha G, Park JI, Jung HJ, Ahmed NU, Kayum MA, Kang JG, et al. 2015. Molecular characterization of BZR transcription factor family and abiotic stress induced expression profiling in Brassica rapa. Plant Physiol. Biochem. 92: 92-104.

Sanghera GS, Wani SH, Hussain W, Singh NB. 2011. Engineering cold stress tolerance in crop plants. Curr. Genomics 12: 30-43.

Savary S, Ficke A, Aubertot JN, Hollier C. 2012. Crop losses due to diseases and their implications for global food production losses and food security. Food Sec. 4: 519-537.

Stotz HU, Mitrousia GK, de Wit PJ, Fitt BD. 2014. Effector-triggered defence against apoplastic fungal pathogens. Trends Plant Sci. 19: 491-500.

Suleman P, Al-Musallam A, Menezes CA. 2001. The effect of solute potential and water stress on black scorch caused by Chalara paradoxa and Chalara radicicola on date palms. Plant Dis. 85: 80-83.

Thakur M, Sohal BS. 2013. Role of elicitors in inducing resistance in plants against pathogen infection: A review. ISRN Biochem. 2013: 762412.

Todaka D, Nakashima K, Shinozaki K, Yamaguchi-Shinozaki K. 2012. Toward understanding transcriptional regulatory networks in abiotic stress responses and tolerance in rice. Rice (N.Y.) 5: 6.

Ton J, van der Ent S, van Hulten M, Pozo M, van Oosten V, van Loon LC, et al. 2009. Priming as a mechanism behind induced resistance against pathogens; insects and abiotic stress. IOBC/wprs Bull. 44: 3-13.

Vijayvargiya S, Kumar A. 2011. Inluence of salinity stress on plant growth and productivity: Salinity stress influences on plant growth. Lap Lambert Academic Publishers, Saarbrücken, Germany. p.180.

Wang W, Vinocur B, Altman A. 2003. Plant responses to drought, salinity and extreme temperatures: Towards genetic engineering for stress tolerance. Planta 218: 1-14.

Wang Z, Tang J, Hu R, Wu P, Hou XL, Song XM, et al. 2015. Genome-wide analysis of the R2R3-MYB transcription factor genes in Chinese cabbage (Brassica rapa ssp. pekinensis) reveals their stress and hormone responsive patterns. BMC Genomics 16: 17.

Yamaguchi-Shinozaki K, Shinozaki K. 2006. Transcriptional regulatory networks in cellular responses and tolerance to dehydration and cold stresses. Annu. Rev. Plant Biol. 57: 
781-803.

Yasuda M, Ishikawa A, Jikumaru Y, Seki M, Umezawa T, Asami T, et al. 2008. Antagonistic interaction between systemic acquired resistance and the abscisic acidmediated abiotic stress response in Arabidopsis. Plant
Cell 20: 1678-1692.

Yu D, Chen C, Chen Z. 2001. Evidence for an important role of WRKY DNA binding proteins in the regulation of NPR1 gene expression. Plant Cell 13: 1527-1540. 